\title{
Determination of tartaric acid in wines by FIA with tubular tartrate-selective electrodes
}

\author{
M. Goreti F. Sales · Carolina E. L. Amaral \\ C. M. Delerue Matos
}

\begin{abstract}
A flow injection analysis (FIA) system com- prising a tartrate- (TAT) selective electrode has been de- veloped for determination of tartaric acid in wines. Sev- eral electrodes constructed for this purpose had a PVC membrane with a complex of quaternary ammonium and TAT as anion exchanger, a phenol derivative as additive, and a more or less polar mediator solvent. Characterization of the electrodes showed behavior was best for membranes with $o$-nitrophenyl octyl ether as solvent. On injection of $500 \mu \mathrm{L}$ into a phosphate buffer carrier $(\mathrm{pH}=3.1$; ionic strength $10^{-2} \mathrm{~mol} / \mathrm{L}$ ) flowing at $3 \mathrm{~mL} / \mathrm{min}$, the slope was $58.06 \pm 0.6$ with a lower limit of linear range of $5.0 \times$ $10^{-4} \mathrm{~mol} / \mathrm{L}$ TAT and $\mathrm{R}^{2}=0.9989$. The interference of several species, e.g. chloride, bromide, iodide, nitrate, gallic acid, tannin, sucrose, glucose, fructose, acetate, and citrate, was evaluated in terms of potentiometric selectivity coefficients. The Hofmeister series was followed for inorganic species and the most interfering organic ion was citrate. When red and white wines were analyzed and the results compared with those from an independent method they were found to be accurate, with relative standard deviations below $5.0 \%$.
\end{abstract}

\section{Introduction}

One of the most important chemical characteristics of wines is their acid content. The non-volatile organic acids, usually a mixture of tartaric, malic, citric, succinic, and lactic acids, are the most important. Among these, tartaric acid is considered of prime importance, not only because of its chemical characteristics (it is the strongest and the most dissociated acid) but also for its organoleptic proper- ties and for being the most resistant to bacterial degradation. Its natural source is the grape and the concentration expected in wines is within the range 1500 to $4000 \mathrm{mg} / \mathrm{mL}$ [1]. Both precipitation with calcium and potassium salts and/or attack by lactic bacteria can result in lower values; higher values can result from external addition, for any necessary correction of the final product.

In this sense, the determination of tartaric acid becomes an important factor for quality control of wines. Several procedures have been proposed for this determination, among which the Office International de la Vigne et du vin (OIV) and the Rebelein methods are the most common [2]. The former requires prior separation of interfering compounds by means of an ion-exchange column, addition of "vanadium reagent" after the medium has been strongly acidified, and reading of the absorbance at $490 \mathrm{~nm}$ after exactly $90 \mathrm{~s}$. The latter is a quicker procedure; it involves addition of silver nitrate in acetate medium, carbon (to eliminate the color of wine), and "vanadium reagent". Because filtration is still required before measurement is possible, the method is, however, inadequate for routine determinations.

To enable accurate and quicker measurement without lengthy pretreatment, alternative procedures have subsequently been proposed in the literature. Among these, adaptation of the above-described methods to flow-injection analysis has been proposed [3]. The sample is prepared in acetic acid and injected into a stream of $\mathrm{NaVO}_{3}$ in acetate buffer to form the colored complex. The absorbance is measured at $490 \mathrm{~nm}$. Interference from other compounds can occur with this procedure, for which a different system including a dialysis unit with a cellulose acetate membrane was most recently suggested [4]. Other types of flow procedure and optical detection have also been reported in the literature; one example is the stop-flow of a mixture of periodic and tartaric acids with luminol for chemiluminescence readings. Here, the stop period is $30 \mathrm{~min}$, which makes each determination timeconsuming [5].

In the work reported herein an alternative procedure has been established for selective measurement of tartaric 

acid, thus eliminating long pretreatment steps. The construction of TAT-selective electrodes, comprising poly(vinyl chloride) membranes, is proposed. Their insertion into flow-injection analysis systems should enable expeditious determination of TAT.

\section{Experimental}

Apparatus

Potential differences between the indicating and reference electrodes were measured by means of a Crison $\mu \mathrm{pH} 2002$ decimillivoltammeter $( \pm 0.1 \mathrm{mV}$ sensitivity) coupled to a Metrohm E 586 recorder. The reference electrode was an Orion, 90-02-00, doublejunction electrode. The selective electrode, with no internal reference solution, was tubular in configuration and constructed as described by Alegret et al. [6]. $\mathrm{pH}$ was measured by means of a Sentek 71728 combined glass electrode.

The FIA system comprised a Gilson Minipuls 2 peristaltic pump, fitted with PVC tubing ( $1.85 \mathrm{~mm}$ i.d.) and a four-way Rheodyne 5020 injection valve. All components were connected by PTFE tubing (Omnifit, Teflon, $0.8 \mathrm{~mm}$ i.d.), Gilson end-fittings, and connectors. The support devices for tubular and reference electrodes and the ground electrode were constructed as described by Alegret et al. [7].

Reagents and solutions

All chemicals were of analytical grade, and deionized water (conductivity $<0.1 \mu \mathrm{S} / \mathrm{cm}$ ) was used.

Disodium tartrate (NaTAT, Sigma), sodium sulfate (Fluka), $o$-phosphoric acid (85\%, Merck), and potassium dihydrogen phosphate (Riedel-de Haën) were used throughout. bis(Triphenylphosphoranyliden)ammonium (BTPPIA) chloride (Aldrich), L-tartaric acid (Fluka), bis(2-ethylhexyl)sebacate (bEHS, Fluka), o-nitrophenyl octyl ether (oNFOE, Fluka), dibutyl phthalate (DBF, Fluka), 4-tert-octylphenol (TOP, Fluka), poly(vinyl chloride) of high molecular weight (PVC, Fluka), and tetrahydrofuran (THF, Riedel-de Haën) were employed for preparation of the selective membrane. Sodium hydroxide (Merck), concentrated sulfuric acid (Merck), potassium chloride (Merck), potassium bromide (Merck), potassium iodide (Merck), potassium nitrate (Riedel-de Haën), gallic acid (Fluka), tannin (Riedel-de Haën), sucrose (Merck), glucose (Merck), fructose (Merck), sodium acetate (Merck), and sodium citrate (Riedel-de Haën) were used to evaluate the effects of both $\mathrm{pH}$ and interfering ionic species.

The ionic strength (IS) was adjusted to $10^{-2} \mathrm{~mol} / \mathrm{L}$ by means of $3.3 \times 10^{-3} \mathrm{~mol} / \mathrm{L} \mathrm{Na}_{2} \mathrm{SO}_{4}$ solution. Simultaneous adjustment of $\mathrm{pH}$ and ionic strength (IS) was achieved with $\mathrm{H}_{3} \mathrm{PO}_{4}-\mathrm{NaH}_{2} \mathrm{PO}_{4}$ buffer solution of $\mathrm{pH} 3.1$ and $10^{-2} \mathrm{~mol} / \mathrm{L}$ IS.

Apart from other chemicals, each carrier solution contained $1 \times$ $10^{-6} \mathrm{~mol} / \mathrm{L} \mathrm{NaTAT}$, both to stabilize the baseline and to preserve the selective membrane. All standard solutions injected inside the manifold were prepared by accurate dilution of $1.0 \times 10^{-1} \mathrm{~mol} / \mathrm{L}$ stock solution with carrier containing no NaTAT.

The influence of $\mathrm{pH}$ was studied for $1.0 \times 10^{-2} \mathrm{~mol} / \mathrm{L}$ NaTAT solution. Interference from other chemicals was determined by the separated-solutions method [8], for which $1.0 \times 10^{-3}, 5.0 \times 10^{-3}$, and $1.0 \times 10^{-2} \mathrm{~mol} / \mathrm{L}$ solutions of NaTAT and potassium chloride, potassium bromide, potassium iodide, potassium nitrate, gallic acid, tannin, sucrose, glucose, fructose, sodium acetate, or sodium citrate were prepared. All these solutions were prepared in $3.3 \times$ $10^{-4} \mathrm{~mol} / \mathrm{L} \mathrm{Na}_{2} \mathrm{SO}_{4}$.

\section{Construction of TAT-selective electrodes}

The anionic exchanger, BTPPIA-TAT, was prepared by a precipitation reaction between $50.0 \mathrm{~mL} 1 \times 10^{-2} \mathrm{~mol} / \mathrm{L} \mathrm{L}$-tartaric acid so-
Table 1 Overall composition of the membranes (\%, w/w) of the TAT-selective electrodes

\begin{tabular}{lccc} 
Components & $\mathrm{A}$ & $\mathrm{B}$ & $\mathrm{C}$ \\
\hline Ionic sensor & 0.8 & 0.9 & 0.9 \\
$o$ NFOE & 65.1 & - & - \\
bEHS & - & 64.8 & - \\
DBF & - & - & 64.0 \\
4-tert-Octylphenol & 7.3 & 7.7 & 7.6 \\
PVC & 26.8 & 26.6 & 27.5 \\
\hline
\end{tabular}

lution and $100.0 \mathrm{~mL} 1 \times 10^{-2} \mathrm{~mol} / \mathrm{L}$ BTPPIA chloride solution. The sensor started precipitating only after adjustment of the $\mathrm{pH}$ of the final solution to 3.9 with small amounts of saturated $\mathrm{NaOH}$ solution. After thorough washing with water the filtered precipitate was kept in a dark flask in a dessicator to prevent light and humidity degradation.

Sensor solutions Types A, B, and C were prepared by dissolving approximately $0.005 \mathrm{~g}$ (measured accurately) ionic sensor and $0.050 \mathrm{~g}$ TOP in $0.400 \mathrm{~g} o \mathrm{NFOE}$, bEHS or DBF, respectively. The corresponding membrane solutions were prepared by mixing these solutions with $0.180 \mathrm{~g}$ PVC in approximately $4.0 \mathrm{~mL}$ THF.

Each of the membranes, the compositions of which are indicated in Table 1, was applied to a tubular conductive support of graphite and epoxy resin [6]. The selective electrodes obtained will be further denoted Types A, B, and C, according to the sensor solutions they contain.

\section{Procedures}

The working characteristics of the tubular TAT-selective electrodes were evaluated by use of a carrier solution of either IS adjuster or $\mathrm{pH}$ and IS adjuster. The injection volume of the FIA system (Fig. 1) was $500 \mu \mathrm{L}$ and the flow rate of solutions through the detector was $3 \mathrm{~mL} / \mathrm{min}$.

The selectivity study was performed by separately injecting $500 \mu \mathrm{L}$ NaTAT solution and other possible interfering compound solutions into the carrier stream of $3.3 \times 10^{-4} \mathrm{~mol} / \mathrm{L} \mathrm{Na}_{2} \mathrm{SO}_{4}$ flowing at $3 \mathrm{~mL} / \mathrm{min}$.

To study the effect of $\mathrm{pH}$ on the potentiometric detector response, a small alteration in the manifold was required [9]. The $\mathrm{pH}$ of $200.0 \mathrm{~mL}$ NaTAT $\left(1.0 \times 10^{-2} \mathrm{~mol} / \mathrm{L}\right)$ in $3.3 \times 10^{-4} \mathrm{~mol} / \mathrm{L}$ $\mathrm{Na}_{2} \mathrm{SO}_{4}$ was altered by addition of small amounts of saturated $\mathrm{NaOH}$ solution or concentrated $\mathrm{H}_{2} \mathrm{SO}_{4}$. These particular solutions were selected for $\mathrm{pH}$ changes to prevent significant volume increments during the trial, and the introduction into the system of foreign chemical species (i.e. species different from those already present: $\mathrm{Na}^{+}, \mathrm{SO}_{4}{ }^{2-}$, and TAT). For each different $\mathrm{pH}$ investigated, $500 \mu \mathrm{L}$ was introduced into a $3 \mathrm{~mL} / \mathrm{min}$ carrier stream of $3.3 \times$ $10^{-4} \mathrm{~mol} / \mathrm{L} \mathrm{Na}_{2} \mathrm{SO}_{4}$.

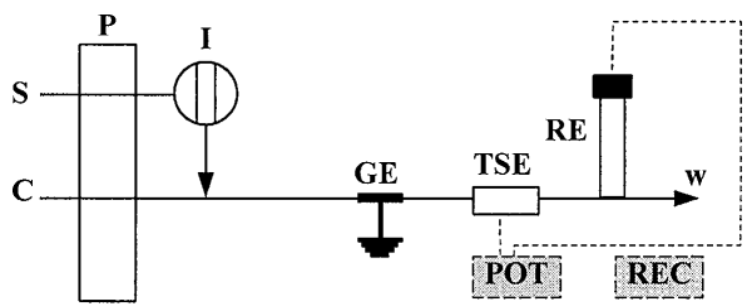

Fig. 1 Flow-injection manifold. P: peristaltic pump; S: sample C: carrier $\left(\mathrm{Na}_{2} \mathrm{SO}_{4} 3.3 \times 10^{-4} \mathrm{~mol} / \mathrm{L}\right.$, IS adjuster or $\mathrm{pH}$ and IS adjuster; with $1 \times 10^{-6} \mathrm{~mol} / \mathrm{L}$ NaTAT); I: injection valve $(500 \mu \mathrm{L})$; GE: grounding electrode; TSE: TAT-selective electrode; RE: reference electrode; w: waste; POT: decimillivoltammeter; REC: recorder. Flow-rate $3 \mathrm{~mL} / \mathrm{min}$ or $8 \mathrm{~mL} / \mathrm{min}$ 
Wine samples were analyzed immediately after 10 - or 20 -fold dilution of white or red wines, respectively. Before analysis the potentiometric system was calibrated under the optimum FIA conditions: $500 \mu \mathrm{L}$ and $8 \mathrm{~mL} / \mathrm{min}$ with a carrier stream of buffer (pH 3.1 and $10^{-2} \mathrm{~mol} / \mathrm{L}$ IS).

The results from potentiometric analysis were compared with those obtained by the Rebelein method [10]. White wine samples were mixed with $\mathrm{AgNO}_{3}$ in acetate medium and with decolorizing carbon. Red wines were treated similarly after previous $1: 1$ dilution. After agitating for $10-15 \mathrm{~s}$, vanadate reagent (prepared by dissolving $\mathrm{NH}_{4} \mathrm{VO}_{3}$ in $\mathrm{NaOH}$ and $\mathrm{CH}_{3} \mathrm{COONa}$ solution) was added. The resulting solution was filtered and its absorbance at $530 \mathrm{~nm}$ was recorded. The corresponding concentration was calculated by means of a calibration curve established by similar treatment of standard solutions containing $0.50,1.00,1.50$, and $2.1 \mathrm{~g} / \mathrm{L}$ tartaric acid.

\section{Results and discussion}

To produce TAT-selective electrodes with proper working characteristics, three polymeric membranes were first prepared. These membranes had basically the same overall composition but contained different plasticizers ( $o$ NFOE, bEHS, or DBF), because of the great influence of these components on the potentiometric response. Apart from different chemical structures, they have very different polarity characteristics; $o$ NFOE is the most polar, with a dielectric constant of 23.6 [11].

An additive was present in each membrane to increase its selectivity to the carboxylate anion in TAT, as a result of its ability to form hydrogen bonds [12].

The behavior of every TAT-selective electrode was first investigated, so the best could be selected for analysis of real samples.

\section{Working characteristics of the TAT-selective electrodes}

The working characteristics of the different TAT-selective electrodes were evaluated in the FIA manifold depicted in Fig 1. A $500 \mu \mathrm{L}$ injection volume and a $3 \mathrm{~mL} / \mathrm{min}$ flowrate were selected to establish conditions equivalent to the stationary state. Results obtained when IS was adjusted indicated significant differences among the sensitivities of the three selective electrodes, that of Type A having the highest slope (Table 2), even though its response was less than the Nernstian-predicted value. Because of the twopKa values of tartaric acid, 3.1 and 4.2 [2], an improvement would most probably be obtained below a specific $\mathrm{pH}$.

The influence of $\mathrm{pH}$ was studied with standard and carrier solutions containing a lower concentration of $\mathrm{Na}_{2} \mathrm{SO}_{4}$ than those used for IS adjustment. Because of possible interference from this electrolyte, adjustment of the ionic strength would lead to a potentiometric response that would result from the combined effect of $\mathrm{pH}$ and $\mathrm{SO}_{4}{ }^{2-}$. Complete removal of electrolyte from the carrier was, on the other hand, impossible, because readings of potential were very unstable as a result of inadequate electrical contact between the indicating and reference electrodes. The results obtained were indicative of similar behavior for the three TAT-selective electrodes. Whereas increasing the $\mathrm{pH}$ resulted in an increase in the potential, the opposite effect was observed for recordings at low $\mathrm{pH}$. The operational $\mathrm{pH}$ range was found to be between 3 and 4, where potential changes were $\pm 6 \mathrm{mV}$ (Table 2). Even though these $\mathrm{pH}$ limits were related to tartaric acid $\mathrm{pKa}$ values, the small $\mathrm{pH}$ range might also have been a consequence of the presence of TOP in the selective membranes - because of its dissociation to phenolate ion, an $\mathrm{H}^{+}$exchanger would also be present within the membrane [13].

The behavior of the electrodes was further evaluated under simultaneous adjustment of $\mathrm{pH}$ and IS, selecting here a $\mathrm{pH}$ of 3.1. Results were indicative of improvement of the working characteristics of the three electrodes sensitivity, lower limit of linear range, repeatability of the analytical signal, and linear correlation (Table 2). Curiously, electrode response was also quicker, enabling the reading of more plug solutions per hour. Of the three types of TAT-selective electrodes, those of Type A had better working characteristics, especially sensitivity.

The interference of other compounds with TAT determinations was also evaluated. As in the $\mathrm{pH}$ study, all solutions were prepared in $3.3 \times 10^{-4} \mathrm{~mol} / \mathrm{L} \mathrm{Na}_{2} \mathrm{SO}_{4}$. Potentiometric selectivity coefficients were calculated for $5.0 \times$ $10^{-3} \mathrm{~mol} / \mathrm{L}$ and for several compounds, as indicated in Table 3. When their degree of ionization was unknown, it was assumed that the analytical signal resulted from an anion with a charge of -1 , i.e. interference was assumed to be the highest possible. Succinic acid was not included in

Table 2 Working characteristics of TAT-selective electrodes

\begin{tabular}{|c|c|c|c|c|c|c|}
\hline Working characteristics & \multicolumn{3}{|c|}{ IS $\left(10^{-2} \mathrm{~mol} / \mathrm{L}\right)$} & \multicolumn{3}{|c|}{$\mathrm{pH}(3.1)$ and IS $\left(10^{-2} \mathrm{~mol} / \mathrm{L}\right)$} \\
\hline Slope $\left(\mathrm{mV}\right.$ decade $\left.{ }^{-1}\right)$ & $43.7 \pm 1.3$ & $11.7 \pm 1.3$ & $24.2 \pm 1.6$ & $58.0 \pm 0.6$ & $15.3 \pm 0.8$ & $47.2 \pm 0.7$ \\
\hline Repeatability $^{\mathrm{b}}( \pm \mathrm{mV})$ & $\pm 0.8(1.6 \%)$ & $\pm 0.6(4.1 \%)$ & $\pm 0.9(1.9 \%)$ & $\pm 0.1(0.1 \%)$ & $\pm 0.3(2.7 \%)$ & $\pm 0.2(0.6 \%)$ \\
\hline R squared & $>0.9984$ & $>0.9976$ & $>0.9973$ & $>0.9991$ & $>0.9982$ & $>0.9989$ \\
\hline
\end{tabular}

a lower limit of linear range

$\mathrm{b}$ at $5.0 \times 10^{-3} \mathrm{~mol} / \mathrm{L}$ 
Table 3 Potentiometric selectivity coefficients of TAT-selective electrodes

\begin{tabular}{llll} 
Interference $^{\mathrm{a}}$ & $\mathrm{IS}\left(10^{-2} \mathrm{~mol} / \mathrm{L}\right)$ & \\
\cline { 2 - 4 } & $\mathrm{A}$ & $\mathrm{B}$ & $\mathrm{C}$ \\
\hline Chloride & $-1.995 \pm 0.003$ & $-0.874 \pm 0.009$ & $-1.568 \pm 0.005$ \\
Bromide & $-1.559 \pm 0.002$ & $-1.131 \pm 0.001$ & $-1.310 \pm 0.004$ \\
Iodide & $-0.198 \pm 0.005$ & $-0.379 \pm 0.082$ & $-0.226 \pm 0.006$ \\
Nitrate & $-1.010 \pm 0.024$ & $-0.836 \pm 0.182$ & $-0.956 \pm 0.014$ \\
Gallic acid & $-1.129 \pm 0.018$ & $-0.493 \pm 0.087$ & $-0.672 \pm 0.038$ \\
Tannin ${ }^{\mathrm{b}, \mathrm{c}}$ & $-2.074 \pm 0.008$ & $-0.867 \pm 0.267$ & $-2.258 \pm 0.009$ \\
Acetate & $-1.058 \pm 0.015$ & $-0.061 \pm 0.029$ & $-0.502 \pm 0.008$ \\
Citrate & $-0.059 \pm 0.025$ & $+1.491 \pm 0.122$ & $+0.028 \pm 0.030$ \\
Malate & $-0.120 \pm 0.012$ & $+0.235 \pm 0.032$ & $-0.023 \pm 0.020$ \\
Lactate & $-0.181 \pm 0.008$ & $+0.028 \pm 0.051$ & $-0.015 \pm 0.058$ \\
Glucose & $-2.356 \pm 0.005$ & $-1.277 \pm 0.095$ & $-2.135 \pm 0.004$ \\
Fructose & $-2.068 \pm 0.002$ & $-1.361 \pm 0.046$ & $-1.923 \pm 0.008$ \\
Sucrose & $-2.003 \pm 0.010$ & $-1.264 \pm 0.012$ & $-1.828 \pm 0.007$ \\
\hline
\end{tabular}

$5.0 \times 10^{-3} \mathrm{~mol} / \mathrm{L}$

${ }^{\mathrm{b}}$ the $\mathrm{pH}$ of the solution was adjusted to 6.0 with $\mathrm{NaOH}$

${ }^{c}$ assuming an average molecular weight of $180 \mathrm{~g} / \mathrm{mol}$

this trial, because it is not commonly present in wines. Basically, inorganic interference followed the Hofmeister series: $\mathrm{I}^{-}>\mathrm{NO}_{3}{ }^{-}>\mathrm{Br}^{-}>\mathrm{Cl}^{-}$[14]. Among organic compounds, carbohydrates (glucose, fructose, and sucrose) resulted in the lowest, indeed insignificant, interference. Similarly, both gallic acid, representing here the polyphenols of wines, and tannin did not interfere significantly with the potentiometric response. Carboxylate compounds, particularly citrate, resulted in the highest interference. Unlike acetate, citrate can be present in wines at concentrations ranging from 0 to $500 \mathrm{mg} / \mathrm{L}$ [2], leading to the possibility of inaccurate reading of samples. Nevertheless, the potential measured for a real sample is a combination both of interfering ions and of the TAT ions present in solution, "competing" at the same time for the same membrane. Because the electrodes are constructed for measurement of TAT, and the concentration of citrate in wines is much lower than that expected for tartaric acid, the interference of citrate can probably be ignored. The same can also be said about interference by malic and lactic acids. Another point contributing to the non-interference of these acids would be their lower degree of ionization compared with TAT. Lower coefficients were usually obtained with the Type-A TAT-selective electrode.

Because of its better working characteristics and greater selectivity, the Type-A TAT-selective electrode was used for analysis of wines.

\section{Optimization of FIA}

Because a selective detector was incorporated into the FIA system, a very simple flow manifold was considered. For this reason only injection volume and flow-rate were evaluated. The optimization was multivariate - the analytical signals produced for $100,200,500$, and $1000 \mu \mathrm{L}$ sam- ples were checked at flow-rates of $2,4,6$, and $8 \mathrm{~mL} / \mathrm{min}$. Recordings from each previous condition were mainly evaluated in terms of dispersion [15], for which $5.0 \times$ $10^{-4}, 1.0 \times 10^{-3}$, and $5.0 \times 10^{-3} \mathrm{~mol} / \mathrm{L}$ NaTAT standard solutions were selected. Whereas injection of $200 \mu \mathrm{L}$ resulted in high dispersion values, even for the lowest flowrate, use of $500 \mu \mathrm{L}$ ensured low or even zero dispersion values at every flow-rate tested. These results could, therefore, be a consequence of the response time of the Type-A TAT-selective electrode and the dispersion of the solutions inside the manifold. Considering also that increasing the flow-rate enabled analysis of a greater number of samples/hour, the conditions selected were $500 \mu \mathrm{L}$ and $8 \mathrm{~mL} / \mathrm{min}$.

Assuming the possibility of a change in electrode behavior under the previously selected conditions, the working characteristics of the Type-A selective electrode were re-evaluated. Apart from an increase of analytical frequency, no significant differences were recorded.

\section{Application to real samples}

TAT was determined potentiometrically in wines after calibration of the FIA system under $\mathrm{pH}$ and IS adjustment (Fig. 2). Before injection every sample was diluted to fit the calibration curve. The results obtained for several white and red wines are indicated in Table 4, which lists averages and standard deviations from six determinations. Sampling rates were approximately about 70 samples/h when real samples were injected.

The accuracy of the potentiometric results is apparent from relative errors below 5\%, when compared with the

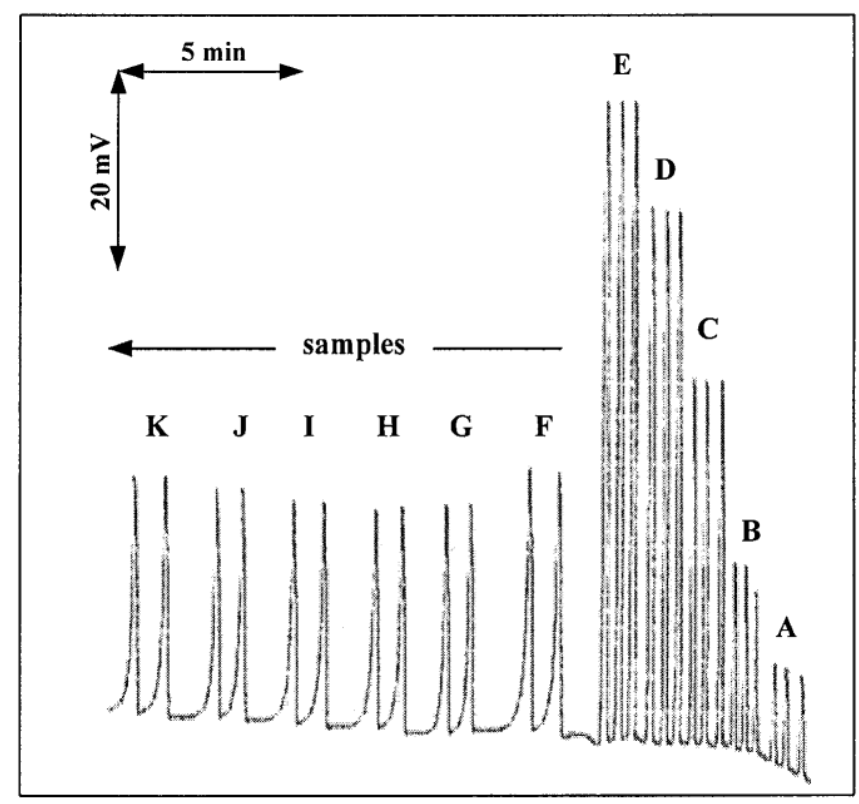

Fig. 2 FIA output for wine analysis $(\mathrm{F}-\mathrm{K})$ preceded by calibration (A-E). A: $7.5 \times 10^{-4} \mathrm{~mol} / \mathrm{L} ; \mathrm{B}: 1.0 \times 10^{-3} \mathrm{~mol} / \mathrm{L} ; \mathrm{C}: 2.0 \times 10^{-3} \mathrm{~mol} / \mathrm{L}$; D: $4.0 \times 10^{-3} \mathrm{~mol} / \mathrm{L}$; E: $6.0 \times 10^{-2} \mathrm{~mol} / \mathrm{L}$; F: red wine $1 ; \mathrm{G}$ : red wine 3; H: red wine 6; I: red wine 2; J: red wine 4 ; $\mathrm{K}$ : red wine 5 
Table 4 Determination of tartaric acid in wines by the proposed FIA system and by the Rebelein method, with the corresponding relative error (RE) and calculated $F$ value

\begin{tabular}{lcccc} 
Samples & TAT $(\mathrm{g} / \mathrm{L})$ & \multirow{2}{*}{\begin{tabular}{l} 
RE \\
\cline { 2 - 3 }
\end{tabular}} & FIA & F test \\
\hline White wine 1 & $1.33 \pm 0.05$ & $1.32 \pm 0.03$ & -0.76 & 2.78 \\
White wine 2 & $1.27 \pm 0.06$ & $1.24 \pm 0.03$ & +2.18 & 4.00 \\
White wine 3 & $1.10 \pm 0.06$ & $1.07 \pm 0.06$ & +2.80 & 1.00 \\
White wine 4 & $1.39 \pm 0.06$ & $1.44 \pm 0.05$ & -3.47 & 1.44 \\
Red wine 1 & $2.56 \pm 0.13$ & $2.64 \pm 0.08$ & -3.03 & 2.64 \\
Red wine 2 & $2.00 \pm 0.10$ & $2.03 \pm 0.12$ & -1.48 & 1.44 \\
Red wine 3 & $2.03 \pm 0.05$ & $2.08 \pm 0.13$ & -2.40 & 6.76 \\
Red wine 4 & $2.12 \pm 0.13$ & $2.08 \pm 0.09$ & +1.92 & 2.09 \\
Red wine 5 & $2.10 \pm 0.13$ & $2.00 \pm 0.13$ & +5.00 & 1.00 \\
Red wine 6 & $1.94 \pm 0.05$ & $2.00 \pm 0.02$ & -3.00 & 6.25 \\
Red wine 7 & $2.05 \pm 0.06$ & $1.97 \pm 0.04$ & +4.06 & 2.25 \\
\hline
\end{tabular}

Rebelein method. In addition, a paired two-tail test for 5\% level of significance gave a calculated $t(0.243)$ below that tabulated $\left(\mathrm{t}_{0.05,10}=1.812\right)$, thus confirming the null hypothesis that the two methods agree. When the variances obtained for each sample were compared by means of the F-test, using the same assumptions as for the Student ttest, the calculated values (Table 4) were always below the critical F-value $\left(\mathrm{F}_{0.025(5,5)}=7.15\right)$, thus confirming the null hypothesis.

In this work we assumed non-interference by malic acid if the amount present was less than $10 \%$ of the tartaric acid content. Higher concentrations of malic acid in wines were not encountered in the samples analyzed.

\section{Conclusions}

If the Type-A membrane is used, determination of TAT in wines by potentiometric detection is a good alternative both to the Rebelein method and to other methods described in the literature. The proposed system is simple, accurate, and inexpensive in terms of reagent consumption and equipment involved, and is suitable for routine application. Sample preparation is achieved by simple dilution; this could be performed automatically by including contluenc e points, reactors of long length, etc., in the FIA manifold.

Because samples with high levels of other organic acids were not tested here, such samples should be investigated before use of this technique for analysis of different kinds of wine, to guarantee the accuracy of the results.

\section{References}

1. Gayon JR, Peynaud E, Sudraud P, Gayon PR (1982) Sciences et Techniques du Vin I - Analyse et Contrôle des Vins, Dunod, Paris

2. Garcia ASC (1988) Controlo de Qualidade em Vinhos Química Enológica - Métodos Analíticos, Instituto do Vinho e da Vinha, Lisboa, p. 310

3. Lazaro F, Castro MDL, Valcarcel M (1986) Analyst 111:729

4. Rangel AOSS, Toth IV (1998) Analyst 123:661

5. Gaikwad A, Silva M, Bendito DP (1994) Analyst 119:1819

6. Alegret S, Alonso J, Bartroli J, Paulis JM, Lima JLFC, Machado AASC (1984) Anal Chim Acta 164:147.

7. Alegret S, Alonso J, Bartroli J, Machado AASC, Lima JLFC, Paulis JM (1987) Quim Anal 6:278

8. Van der Linden WE (IUPAC) (1994) Pure Appl Chem 66: 2527

9. Alegret S, Alonso J, Bartroli J, Lima JLFC, Machado AASC, Paulis JM (1985) Anal Lett 18:2291

10. Rebelein H (1974) Feuillets verts de l'OIV, : 467

11. Okada T, Sugihara H, Hiratani K (1995) Analyst 120:2381

12. Hara H, Okazaki S, Fujinaga T (1980) Anal Chim Acta 121: 119

13. Hara H, Kondoh Y, Mitani O, Okazaki S (1990) Anal Chem 62: 1139

14. Morf WE (1981) The principals of ion-selective electrodes and of membrane transport, Elsevier, Amsterdam

15. Trojanowicz M, Matuszewski W (1982) Anal Chim Acta 138: 71 